\title{
Optimized design and experiment of the three-arm transplanting mechanism for rice potted seedlings
}

\author{
Jianjun Yin, Zeliang Wang, Maile Zhou*, Luning Wu, Yan Zhang \\ (School of Agricultural Engineering, Jiangsu University, Zhenjiang 212013, Jiangsu, China)
}

\begin{abstract}
The transplanting arm of two-arm transplanting mechanism is easy to cause seedlings injury and missing due to its faster speed relative to the seedlings. In order to solve the existed problems, a three-arm transplanting mechanism for rice potted seedlings was developed in this study. The developed three-arm transplanting mechanism for rice potted seedling can make the transplanting arm realize special trajectory and attitude through the unequal planetary gear transmission. The kinematic model of three-arm transplanting mechanism for rice potted seedling was established, and the optimal design software was developed. Based on the heuristic optimization algorithm named "parameter guide", a set of satisfied mechanism parameters required by the rice potted seedling transplanting were obtained. The trajectory and attitude of three-arm transplanting mechanism used for the rice potted seedling were analyzed. Besides, the virtual simulation results were basically consistent with the optimization software results, and the correctness of theoretical analysis and virtual simulation were also verified by each other. When the developed transplanting mechanism picked up the seedling, the velocity of transplanting arm relative to the seedling was reduced by about $30 \%$. The results showed that the injury rate of rice potted seedling transplanting mechanism was $0.04 \%$, the missing rate of seedling was $1.4 \%$, the integrity rate of seedling pot matrix was $96 \%$, and the success rate of picking seedling was $99.92 \%$.
\end{abstract}

Keywords: agricultural machinery, transplanting mechanism, rice potted seedling, three-arm, optimal design DOI: $10.25165 /$ j.ijabe.20211405.6844

Citation: Yin J J, Wang Z L, Zhou M L, Wu L N, Zhang Y. Optimized design and experiment of the three-arm transplanting mechanism for rice potted seedlings. Int J Agric \& Biol Eng, 2021; 14(5): 56-62.

\section{Introduction}

Two typical mechanized transplanting methods are often used for rice, including blanket seedling transplanting and potted seedling transplanting ${ }^{[1-3]}$. Blanket seedling transplanting method takes off the seedling blocks through the transplanting mechanism and plants them in the paddy field, which will cause the seedling injury and the prolonged turning-green stage $^{[4-6]}$. The transplanting of rice potted seedlings is to transplant the seedlings with independent rice pot matrix, which is conducive to the strong seedlings cultivation, effective tillers (increased by $20 \%$ in low stalk position), fertilizer and water saving, and the average production will increase by more than $10 \%$. At present, there are three main ways for mechanized rice potted seedling picking: top-out type, pneumatic type and clamping type. The clamping transplanting mechanism can separate the seedling from the tray by clamping the stem or the substrate of the rice potted seedling ${ }^{[7-9]}$. The top-out type transplanting mechanism relies on the top rod to top the seedlings from the back of the hole plate to achieve picking seedling action ${ }^{[10]}$. The pneumatic transplanting device relies on the air force to blow (suck) seedlings out of the tray. In the

\section{Received date: 2021-06-18 Accepted date: 2021-09-07}

Biographies: Jianjun Yin, PhD, Professor, research interests: optimal design of agricultural machinery, Email: yinjianjun@ujs.edu.cn; Zeliang Wang, Master candidate, research interests: transplanting equipment, Email: w7678041956@ 163.com; Luning Wu, Master candidate, research interests: transplanting equipment, Email: dtdsrt@163.com; Yan Zhang, Master candidate, research interests: transplanting equipment, Email: zhangyan3819@163.com.

*Corresponding author: Maile Zhou, $\mathrm{PhD}$, Associate Professor, research interests: design and application of agricultural machinery. School of Agricultural Engineering, Jiangsu University, Zhenjiang 212013, China. Tel: +86-15051140832, Email: zhoumaile@126.com. nineties of the last century, Japan produced the top-out type transplanter for rice potted seedling, which was equipped with the following operations: pushing, conveying and planting. The mechanism was complex and the efficiency was low. Zhang et al. ${ }^{[1]}$ designed a top-out type rice potted seedling orderly transplanter, which pushed out the seedlings from the back of the tray and planted them into the paddy field through the guide tube, and established the theoretical model of the drop movement of the potted seedling in the air and the sliding movement on the guide tube. Bao et al. ${ }^{[12]}$ proposed an orderly transplanting scheme of rice potted seedling and developed a kind of horizontal and vertical box moving device and planting device. Through the experimental research on the tensile properties and pulling performance of rice potted seedlings. Song et al. ${ }^{[13]}$ concluded that the tensile breaking force of seedlings is far greater than the force required to pull seedlings from tray. On this basis, the 2ZPY-H530 rice potted seedling transplanter was developed. Yu et al. ${ }^{[14]}$ proposed a clamping type rice potted seedling transplanting mechanism with the non-circular incomplete gear to realize the unequal speed transmission ratio, and the average success rate of seedling picking can reach $93.06 \%$. Wu et al. ${ }^{[15,16]}$ proposed a design method combining the forward design of rice seedling transplanting mechanism with the reverse design of local trajectory fine-tuning, which can obtain better working trajectory and attitude. Cai et al. ${ }^{[17]}$ designed a potted seedling transplanting device with variable row spacing, and completed the kinematic analysis and parameter optimization of the seedling picking linkage mechanism. As a result, the average success rate of seedling picking was $89.96 \%$, and the average fallen seedling rate was $3.45 \%$. Zhou et al. ${ }^{[18,19]}$ proposed a design method of Bezier gear by fitting Bezier curve, and designed a two-arm transplanting mechanism of rice potted seedlings. The mechanism can complete two transplanting 
actions in one rotation, and the operation efficiency can reach 300 holes/min. Here many kinds of transplanting mechanisms are summarized: the clamping transplanting mechanism has a large response to the seedling picking speed and attitude, which will be easy to cause seedling injury; the top-out type transplanting mechanism has high requirements for plug, which is difficult to be popularized and applied; the pneumatic transplanting device needs to add the air pump, which has a high cost and complex structure. In addition, most of the existing rice potted seedling transplanting equipment has low operation efficiency, which will cause problems such as low transplanting success rate and seedling injury.

In this study, a three-arm transplanting mechanism was developed for the rotary transplanting mechanism of rice potted seedling, which realized the required trajectory and attitude of rice potted seedling transplanting by the unequal speed transmission of non-circular gear train. During the working process, the three transplanting arms alternately complete the action of picking, transporting and planting, and complete three transplanting actions in a work cycle, and the velocity of transplanting arm is relatively low when picking seedlings, so as to ensure the integrity of seedling pot matrix, which will improve the success rate of picking seedlings and reduce the injury rate of seedlings.

\section{Composition and working principle}

The three-arm transplanting mechanism for rice potted seedling is composed of non-circular gear train and three transplanting arms, as shown in Figure 1. The non-circular gear train is composed of seven non-circular gears and planet carrier, the tooth profiles of three intermediate gears are consistent, and three planet gears are consistent. The planet carrier is hinged on the frame and rotates at a constant speed relative to the frame. The sun gear is fixedly connected with the frame, and the other six non-circular gears are hinged on the planet carrier. During the working process, the planet carrier rotates clockwise, the sun gear is meshed with the intermediate gears at the same time, and the intermediate gears are meshed with the planetary gears respectively. Transplanting arms are respectively fixed on planetary gears. The planet carrier rotates at a constant speed. On the one hand, the transplanting arm rotates with the circumference of the planet carrier, and on the other hand, it rotates with the planet gear at unequal speeds relative to the planet carrier. The two motions are combined to make the transplanting arm realize the transplanting trajectory and attitude.

The transplanting arm is mainly composed of a transplanting arm shell, a pair flake of seedling clamp, a seedling push rod, an appliance of seedling clamp, a seedling pusher, a cam and a fork, etc. as shown in Figure 2. The cam is fixed on the planet carrier, and the shift fork is hinged on the transplanting arm shell, and the transplanting arm shell rotates with the planet gear relative to the cam (planet carrier), and the cam and the shift fork constitute a cam mechanism in the form of a swing follower. The end of the shift fork away from the cam controls the seedling push rod to make a reciprocating linear motion. The appliance of seedling clamp and the seedling pusher are fixed on the seedling push rod. The seedling clamp is arranged on the inner side of a pair flake of seedling clamp, and the seedling pusher is arranged under a pair flake of seedling clamp. The working process of the seedling clamping device is shown in Figure $2 b$. In the initial position, the appliance of seedling clamp is used to open the pair flake of seedling clamp from the inner side of a pair flake of seedling clamp. When the transplanting mechanism moves to the seedling clamping position, the push rod drives the appliance of seedling clamp to recover, and the appliance of seedling clamp is out of contact with the flake of seedling clamp. A pair flake of seedling clamp is quickly closed under the action of their own elasticity to clamp their inner seedlings. When the transplanting mechanism moves to the seedling planting position, the shift fork moves to the gap of the cam, and the seedling pushing rod is quickly pushed out under the action of the seedling pushing spring, and the appliance of seedling clamp fixed on the seedling pushing rod opens the two flake of seedling clamp from the inside. At the same time, the seedling pusher fixed on the foremost end of the seedling rod acts on the seedling pot matrix to push the seedlings into the paddy field.
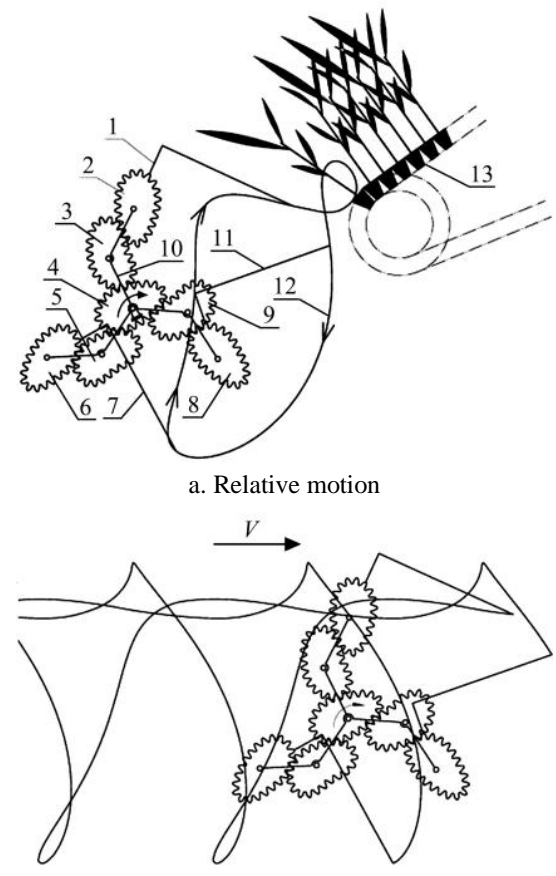

b. Absolute movement

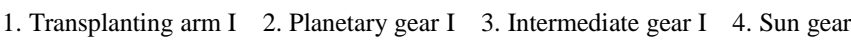
5. Intermediate gear II 6. Planetary gear II 7. Transplanting arm II 8. Planetary gear III 9. Intermediate gear III 10. Planet carrier 11. Transplanting arm III 12. Relative motion trajectory 13. Rice potted seedlings

Figure 1 Working principle diagram of three-arm transplanting mechanism for rice potted seedlings

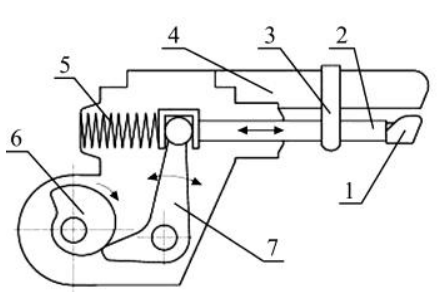

a. Transplanting arm

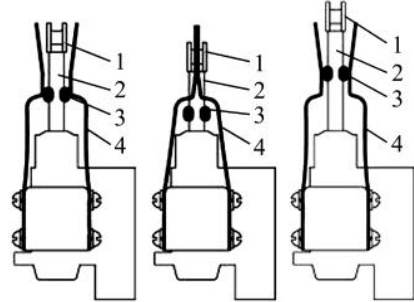

b. Seedling clamping device
1. Seedling pusher 2. Seedling push rod 3. Appliance of seedling clamp $\begin{array}{llll}\text { 4. Flake of seedling clamp 5. Seedling pushing spring } & \text { 6. Cam 7. Fork }\end{array}$

Figure 2 Schematic diagram of transplanting arm and seedling clamping device

\section{Kinematic analysis}

The three-arm transplanting mechanism for rice potted seedlings consists of the driving components and the executive components. The driving components are a variable speed planetary gear train, and the executive components are the transplanting arms. In this study, a coordinate system was 
established with the rotation center of the planet carrier as the coordinate origin (Figure 3), and the rotation angle of the planet carrier was used as the independent variable to establish the functional relationship between transplanting arm and mechanism parameters, named the kinematics theory model.

Point set on the driving gear pitch curve

$$
\left(\rho_{i}, \theta_{i}\right), i=1,2,3, \ldots, 360
$$

where, $\rho_{i}$ is the radial diameter, $\mathrm{mm} ; \theta_{i}$ is the polar angle, $\left({ }^{\circ}\right)$.

The average transmission ratio of non-circular gears in this study is 1 .

$$
\left\{\begin{array}{l}
\rho_{i}+\rho_{i}^{\prime}=\overline{o_{1} o_{2}} \\
\sum\left(\theta_{i+1}-\theta_{i}\right) \frac{\rho_{i}}{\rho_{i}^{\prime}}=2 \pi
\end{array}\right.
$$

where, $\rho_{i}^{\prime}$ is the radial diameter of driven gear, mm; $\overline{o_{1} o_{2}}$ is the center distance, $\mathrm{mm}$.

$$
\theta_{i}^{\prime}=\theta_{i-1}^{\prime}+\left(\theta_{i+1}-\theta_{i}\right) \frac{\rho_{i}}{\rho_{i}^{\prime}}
$$

where, $\theta_{i}{ }^{\prime}$ is the polar angle of driven gear, $\left(^{\circ}\right)$.

Planet carrier rotation angle is $\theta$. Absolute angle of planet carrier $\varphi_{H}$ :

$$
\varphi_{H}(\theta)=\varphi_{0}-\theta
$$

Absolute angle of sun gear $\varphi_{1}$ :

$$
\varphi_{1}(\theta)=\varphi_{0}
$$

Absolute angle of intermediate gear $\varphi_{2}$ :

$$
\varphi_{2}(\theta)=\varphi_{H}(\theta)-\varphi_{2 H}(\theta)
$$

Among them, $\varphi_{2 H}$ is the angle of intermediate gear relative to planet carrier.

$$
\varphi_{2 H}(\theta)=\sum_{i=0}^{\theta} \frac{\rho_{i}}{\rho_{i}^{\prime}}\left(\theta_{i+1}-\theta_{i}\right)
$$

Absolute angle of planetary gear $\varphi_{3}$ :

$$
\varphi_{3}(\theta)=\varphi_{H}(\theta)+\gamma_{0}-\varphi_{30}+\varphi_{3 H}(\theta)
$$

where, $\varphi_{3 H}$ is the angle of planetary gear relative to planet carrier, $\left({ }^{\circ}\right) ; \varphi_{30}$ is the initial rotation angle of planetary gear, $\left(^{\circ}\right)$.

$$
\begin{gathered}
\varphi_{3 H}(\theta)=\sum_{\gamma_{0}}^{\varphi_{2 H}(\theta)+\gamma_{0}} \Delta \varphi_{2 H} \frac{\rho_{i}}{\rho_{i}^{\prime}} \\
\varphi_{30}=\sum_{0}^{\gamma_{0}} \frac{\rho_{i}^{\prime}}{\rho_{i}}
\end{gathered}
$$

The coordinates of the center of rotation of the sun gear:

$$
\left\{\begin{array}{l}
x_{o 1}(\theta)=0 \\
y_{o 1}(\theta)=0
\end{array}\right.
$$

The coordinates of the center of rotation of the intermediate gear:

$$
\left\{\begin{array}{l}
x_{o 2}(\theta)=\overline{o_{1} o_{2}} \cos \left[\varphi_{H}(\theta)\right] \\
y_{o 2}(\theta)=\overline{o_{1} o_{2}} \sin \left[\varphi_{H}(\theta)\right]
\end{array}\right.
$$

The coordinates of the center of rotation of the planetary gear:

$$
\left\{\begin{array}{l}
x_{o 3}(\theta)=x_{o 2}(\theta)+\overline{o_{1} o_{2}} \cos \left[\varphi_{H}(\theta)+\gamma_{0}\right] \\
y_{o 3}(\theta)=y_{o 2}(\theta)+\overline{o_{1} o_{2}} \sin \left[\varphi_{H}(\theta)+\gamma_{0}\right]
\end{array}\right.
$$

The trajectory formed by the end of the transplanting arm:

$$
\left\{\begin{array}{l}
x_{D 1}(\theta)=x_{o 3}(\theta)+S \cos \left[\varphi_{3}(\theta)+\beta_{0}\right] \\
y_{D 1}(\theta)=y_{o 3}(\theta)+S \sin \left[\varphi_{3}(\theta)+\beta_{0}\right]
\end{array}\right.
$$

where, $\beta_{0}$ is the initial installation angle of transplanting arm, $\left({ }^{\circ}\right)$.

The trajectory and attitude of the transplanting arms are the same, and there is only one phase difference. The kinematic formulas of transplanting arm II and transplanting arm III can be obtained by rotating the transplanting arm I and the planetary carrier $120^{\circ}$ and $240^{\circ}$, respectively.

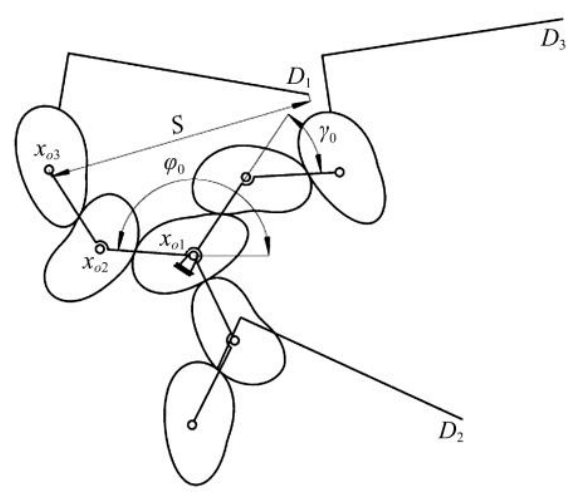

a. Initial installation location

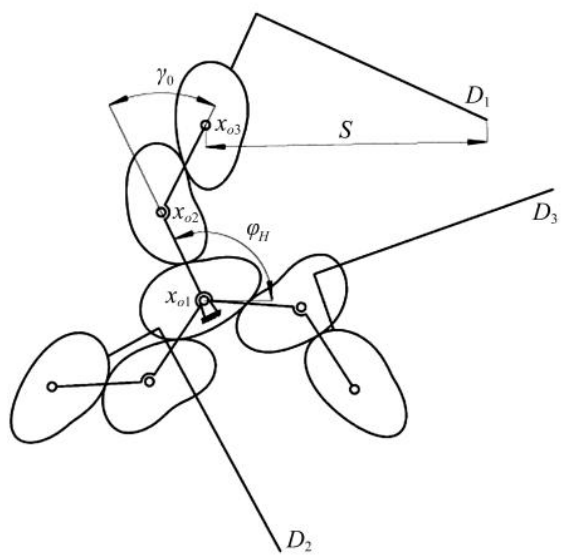

b. A certain working position

Figure 3 Schematic diagram of three-arm transplanting mechanism for rice potted seedlings

\section{Parameter optimization}

\subsection{Optimal design software and parameter optimization}

Based on the kinematics model of the three-arm transplanting mechanism for rice potted seedlings, an optimal design software for the transplanting mechanism was developed (Figure 4). Considering the agronomic and institutional operation requirements of rice potted seedling transplanting, here 8 optimal goals of rice potted seedling transplanting mechanism are summarized: 1) these three transplanting arms should not be interfered with each other during work; 2) the angle of the seedling picking should be between $-5^{\circ}$ and $15^{\circ} ; 3$ ) the angle of seedlings pushing should be between $45^{\circ}$ and $65^{\circ}$; 4) angle difference should be between $50^{\circ}$ and $60^{\circ}$; 5) transplanting arms should not push the seedling; 6) the distance between the gearbox and the ground should be greater than $20 \mathrm{~mm}$; 7) the height of trajectory should be greater than $260 \mathrm{~mm}$; 8) non-circular gear modulus should be greater than $2.5 \mathrm{~mm}$. According to the kinematics model, the functional relationship between the optimization goal and the parameters was established, and the transplanting agronomic requirements were also transformed into the digital optimization goals, and embedded in the developed optimal design software in the form of a progress bar.

Based on the developed rice potted seedling transplanting mechanism optimal design software, and based on the "parameter guide" heuristic optimization algorithm ${ }^{[20]}$, a set of mechanism parameters that meet the requirements of rice potted seedling transplanting are obtained: $r_{1}=21 \mathrm{~mm}, \theta_{1}=20^{\circ}, r_{2}=28 \mathrm{~mm}, \theta_{2}=45^{\circ}$, $r_{3}=50 \mathrm{~mm}, \theta_{3}=76^{\circ}, r_{4}=49 \mathrm{~mm}, \theta_{4}=105^{\circ}, r_{5}=58 \mathrm{~mm}, \theta_{5}=132^{\circ}, r_{6}=$ $47 \mathrm{~mm}, \theta_{6}=165^{\circ}, r_{7}=18 \mathrm{~mm}, \theta_{7}=195^{\circ}, r_{8}=12 \mathrm{~mm}, \theta_{8}=225^{\circ}, r_{9}=$ $28 \mathrm{~mm}, \theta_{9}=255^{\circ}, r_{10}=60 \mathrm{~mm}, \theta_{10}=285^{\circ}, r_{11}=48 \mathrm{~mm}, \theta_{11}=316^{\circ}$, $r_{12}=24 \mathrm{~mm}, \theta_{12}=345^{\circ}, \Phi_{0}=86^{\circ}, \beta_{0}=-29^{\circ}, S=145 \mathrm{~mm}, H_{1}=65 \mathrm{~mm}$, 
$\gamma_{0}=-53^{\circ}$. Among them, $\left(r_{\mathrm{i}}, \theta_{\mathrm{i}}\right)$ is the control point of the non-circular gear pitch curve; $\Phi_{0}$ is the initial installation position of the transplanting mechanism; $\beta_{0}$ is the initial angular displacement of the transplanting arm relative to the planetary gear;
$S$ is the distance from the rotation center of the planetary gear to the tip of the transplanting arm; $H_{1}$ is the distance from the rotation center of the planetary gear to the axis of the pusher rod; $\gamma_{0}$ is the corner of the planet carrier.

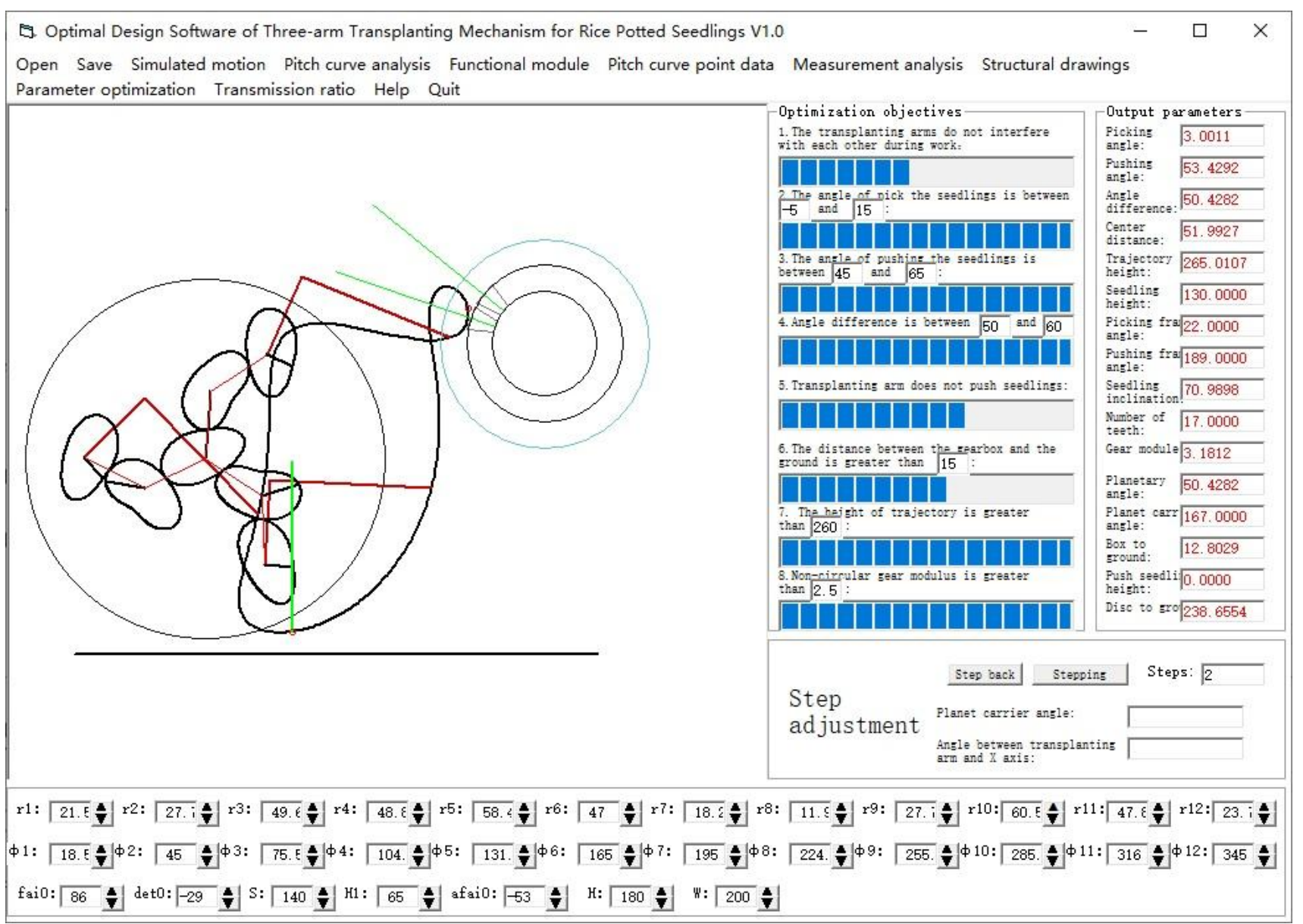

Figure 4 Optimal design software of three-arm transplanting mechanism for rice potted seedlings

Under these sets of parameters, the three transplanting arms could complete the actions of picking, transporting and planting in sequence. When the transplanting mechanism is in the initial position, the transplanting arm I and the transplanting arm II are in the return stage, and the transplanting arm III is in the conveying stage. When transplanting arm I, transplanting arm II and transplanting arm III are in the picking and planting positions, the corresponding planet carrier rotation angles are shown in Table 1.

Table 1 Rotation angles of the transplanting arms

\begin{tabular}{lccc} 
& $\begin{array}{c}\text { Transplanting arm } \\
\text { I }\end{array}$ & $\begin{array}{c}\text { Transplanting arm } \\
\text { II }\end{array}$ & $\begin{array}{c}\text { Transplanting arm } \\
\text { III }\end{array}$ \\
\hline $\begin{array}{c}\text { The location of the } \\
\text { seedling picking }\end{array}$ & $20^{\circ}$ & $140^{\circ}$ & $260^{\circ}$ \\
$\begin{array}{c}\text { The location of the } \\
\text { seedling planting }\end{array}$ & $191^{\circ}$ & $311^{\circ}$ & $71^{\circ}$ \\
\hline
\end{tabular}

Note: $360^{\circ}$ is a working cycle.

\subsection{Analysis of parameter response}

In order to obtain the trajectory law of the influence of the mechanism parameters on the working trajectory of the transplanting mechanism, this study analyzed the corresponding law of the main parameters (Figure 5). The parameter $r_{1}$ has little effect on the trajectory of the seedling removal section, mainly affecting the trajectory height of the return section. The larger the value of $r_{1}$, the smaller the trajectory height of the return section. The parameters $r_{2}-r_{6}$ have a greater impact on the trajectory of the seedling removal section, the return section and the planting point.
As the value increases, the trajectory height of the return section becomes smaller, and the greater the vertical height between the planting point and the seedling removal point, the smaller the loop of the seedling removal segment (the shorter the length of the seedling segment). The parameter $r_{7}$ has a greater impact on the trajectory of the seedling removal section, and less on the trajectory of other sections. The larger the value of $r_{7}$, the shorter the trajectory of the seedling removal section. The influence of $r_{8}-r_{12}$ on the trajectory of the transplanting mechanism becomes stronger and stronger, and the larger the parameter value, the longer the trajectory of the seedling section and the smaller the vertical height between the planting point and the seedling removal point. The parameter $\Phi_{0}$ has no effect on the relative motion trajectory, only affects the degree of inclination of the trajectory. The parameter $\beta_{0}$ has a certain influence on the trajectory of seedling point, transporting section, planting point and return section. The larger the value of $\beta_{0}$, the higher the heights of seedling removal point, planting point and return section. The parameter $S$ has a greater influence on the distance between the trajectory and the transplanting mechanism. As the value of $S$ increases, the farther the trajectory is from the transplanting mechanism, and the longer the seedling removal section. The parameter $\gamma_{0}$ mainly affects the trajectory of the seedling removal section and the planting section. The larger the value of $\gamma_{0}$, the shorter the trajectory of the seedling removal section and the greater the vertical distance between the planting point and the seedling removal point. 


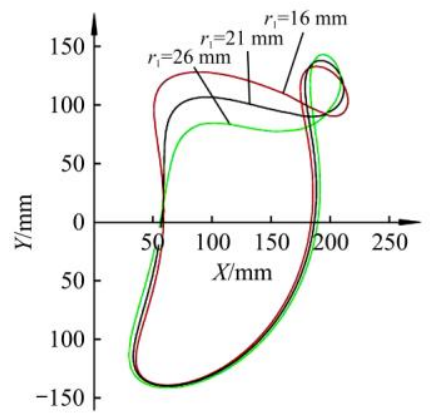

a. The law of $r_{1}$ response to trajectory

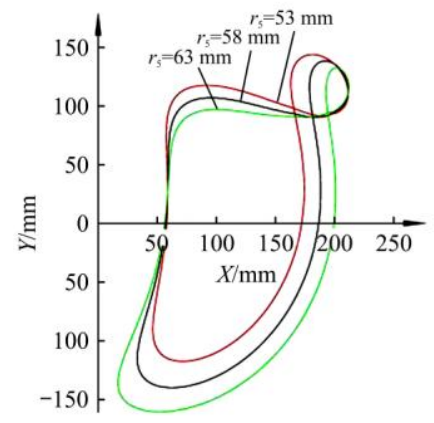

e. The law of $r_{5}$ response to trajectory

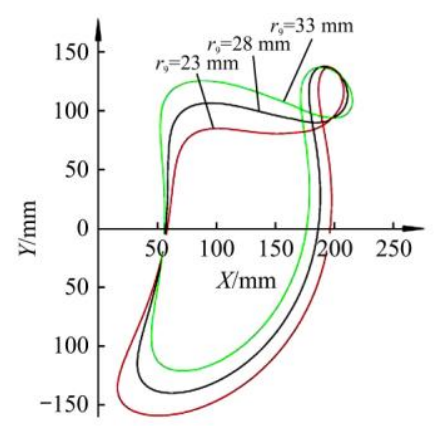

i. The law of $r_{9}$ response to trajectory

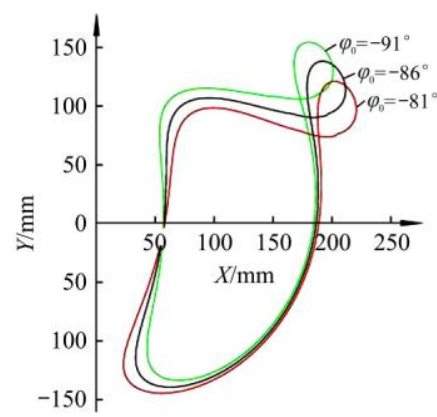

$\mathrm{m}$. The law of $\varphi_{0}$ response to trajectory

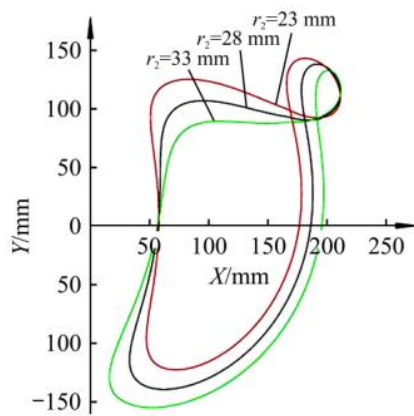

b. The law of $r_{2}$ response trajectory to trajectory

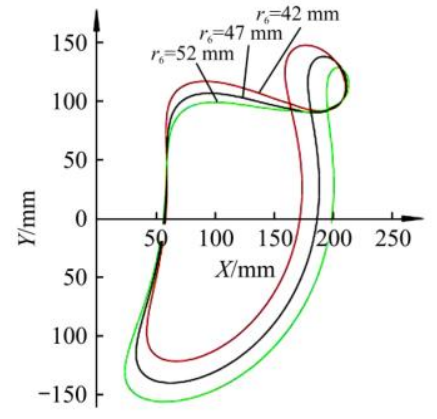

f. The law of $r_{6}$ response trajectory to trajectory

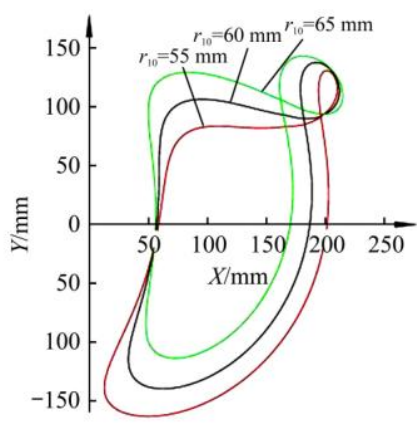

j. The law of $r_{10}$ response trajectory to trajectory

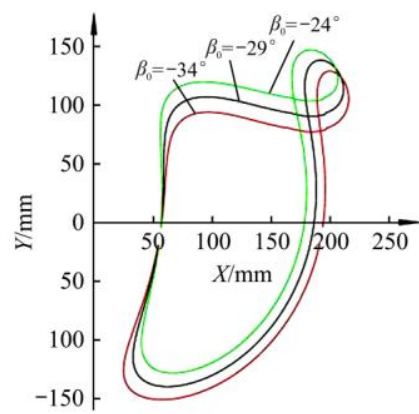

n. The law of $\beta_{0}$ response trajectory to trajectory

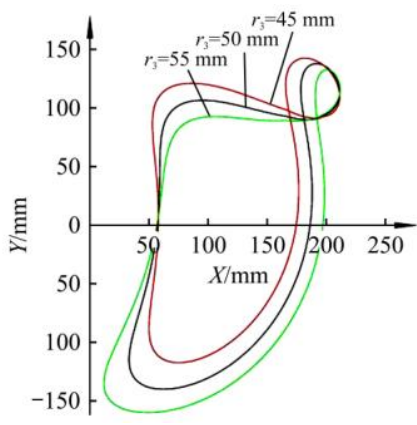

c. The law of $r_{3}$ response to trajectory

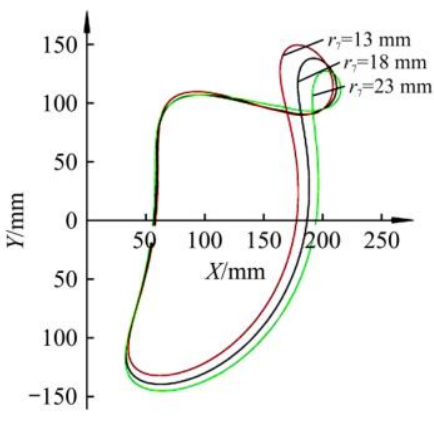

g. The law of $r_{7}$ response to trajectory

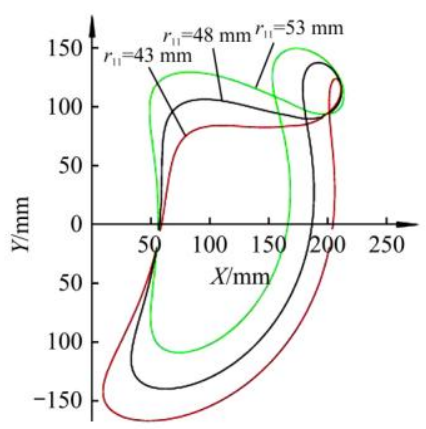

$\mathrm{k}$. The law of $r_{11}$ response to trajectory

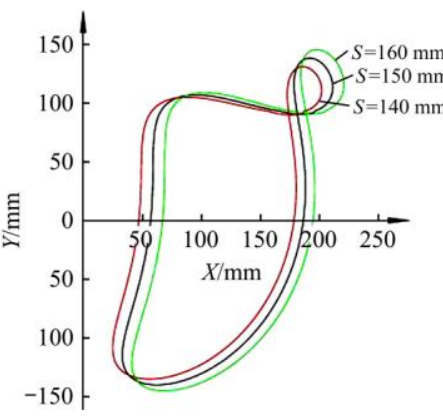

o. The law of $S$ response to trajectory

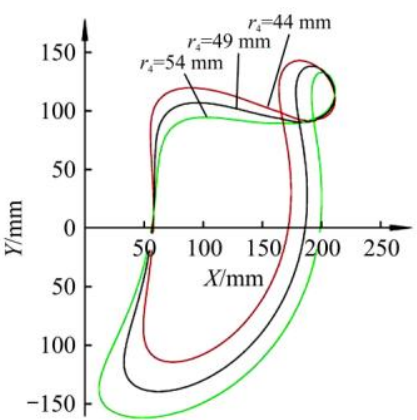

d. The law of $r_{4}$ response trajectory to trajectory

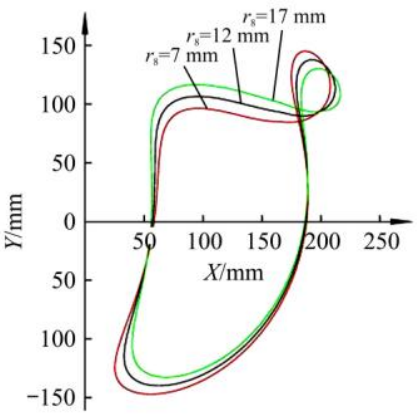

h. The law of $r_{8}$ response trajectory to trajectory

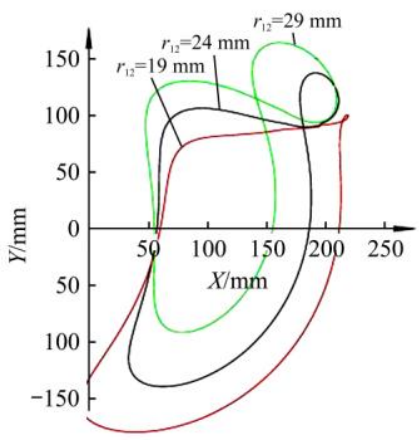

1. The law of $r_{12}$ response trajectory to trajectory

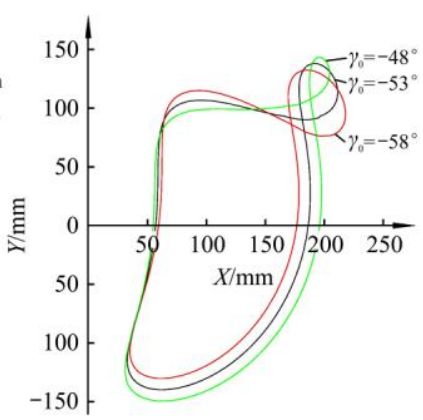

p. The law of $\gamma_{0}$ response trajectory to trajectory

Figure 5 Corresponding law of the main parameters

\section{Experimental research}

\subsection{Virtual experiment}

Based on the optimized mechanism parameters, a virtual prototype of the three-arm transplanting mechanism was established, and the virtual simulation test was performed (Figure 6). The working trajectory and attitude of the transplanting mechanism were obtained through virtual simulation. After comparison, the working trajectory and attitude obtained by virtual simulation are basically consistent with the results of the optimization design software, which mutually verify the correctness among the kinematic analysis, optimization design software and virtual simulation. The displacement curve and velocity curve obtained by virtual simulation are shown in Figures 7 and 8 respectively. It can be seen from the displacement curve that the displacement curve of the three transplanting arms changes with the rotation angle of the planet carrier, and there is a certain phase difference in the movement law of the three transplanting arms. 


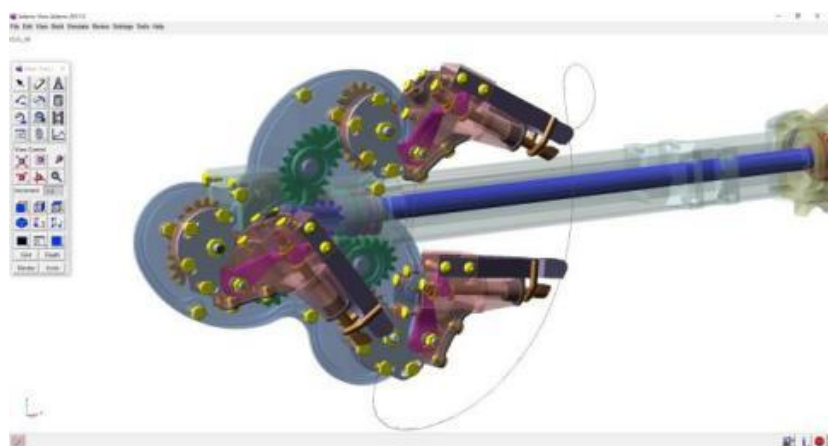

Figure 6 Virtual prototype

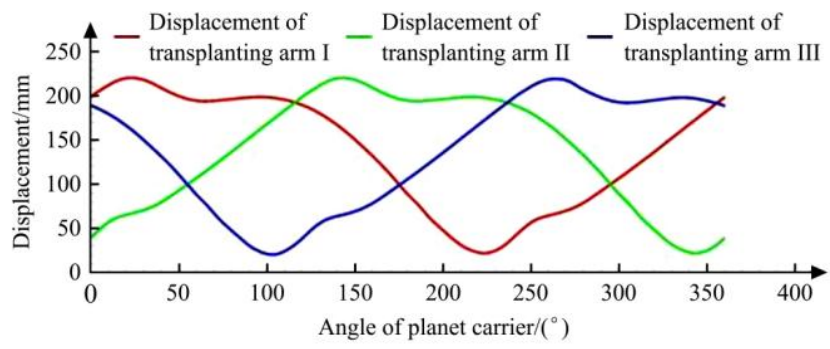

a. Displacement in $X$ direction

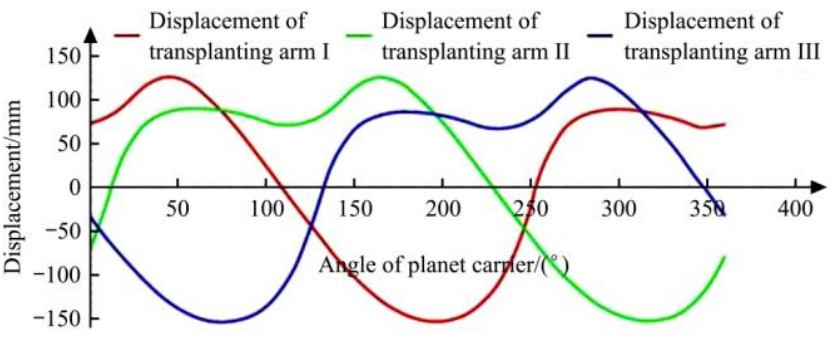

b. Displacement in $Y$ direction

Figure 7 Displacement curve of the transplanting arm

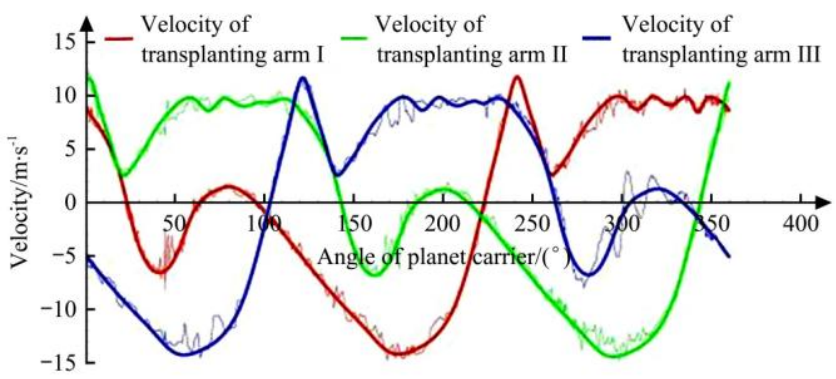

a. Velocity in $X$ direction

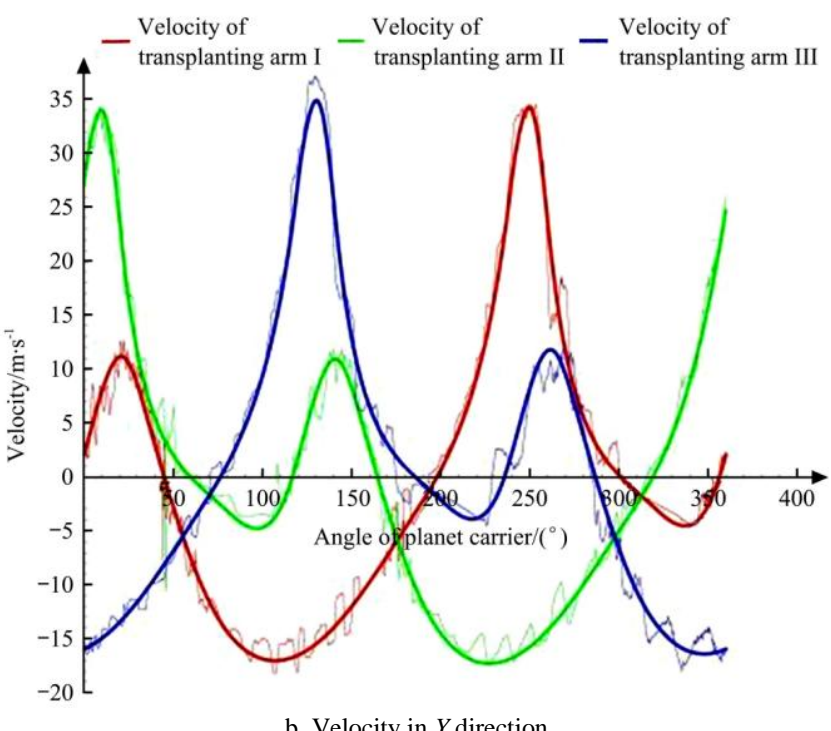

b. Velocity in $Y$ direction

Figure 8 Velocity curve of the transplanting arm
It also can be seen from the speed curve that the movement of the three transplanting arms relative to the frame is more complicated through the non-circular gear planetary gear train with unequal speed transmission. The reason for the slight fluctuation of the speed curve is that the force of the tooth contact force, the contact force between the shift fork and the cam, and the spring force of the pusher spring are added in the virtual simulation environment.

\subsection{Test of picking seedlings}

A three-arm transplanting mechanism test system was developed, and the picking seedling tests were carried out. The test system is based on the rice transplanter chassis, and the power is transmitted to the three-arm transplanting mechanism through bevel gear transmission. The test plug, consisted of 14 holes in the horizontal direction and 29 holes in the vertical direction, with a hole spacing of $20 \mathrm{~mm}$, is a plastic soft plug. The rice potted seedlings are Nanjing 9108, and the seedling age is $30 \mathrm{~d}$. There is no pest and disease, and no connect to the root phenomenon on the surface of the plug. During the test, taking the seedling position as the reference, and after adjusting the seedling box inclination and the initial position of the seedling supply system, then the picking seedling tests were carried out (Figure 9). During the test, the chassis of the rice transplanter was static, and the three-arm transplanting mechanism rotated relative to the chassis. The trajectory, attitude and seedling picking performance of the three-arm transplanting mechanism were verified. Experiments showed that the designed three-arm transplanting mechanism can achieve picking seedling, transporting and planting seedling, and its trajectory and attitude can meet the requirements of rice potted seedling transplanting. Under the same conditions, the speed and seedling picking performance of transplanting arm were also analyzed by high-speed camera technology, compared with the two-arm transplanting mechanism. In the experiment, a Phantom v1.5 digital camera was used, and high-speed photography analysis software (Phantom Camera Control) was used for analysis. The speed of the transplanting arm relative to the seedlings is reduced by about $30 \%$. When the seedling extraction efficiency is 180 holes/min, the seedling injury rate is $0.04 \%$, the seedling missing rate is $1.4 \%$, the seedling pot matrix integrity rate is $96 \%$, and the picking seedling success rate is $99.92 \%$.

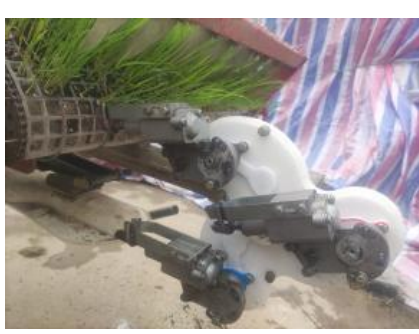

a. Start picking seedlings

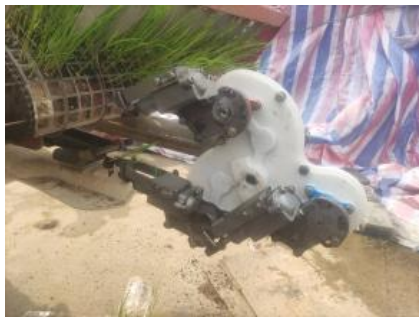

c. Transporting

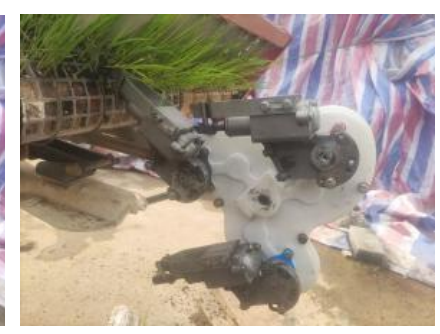

b. End of seedling picking

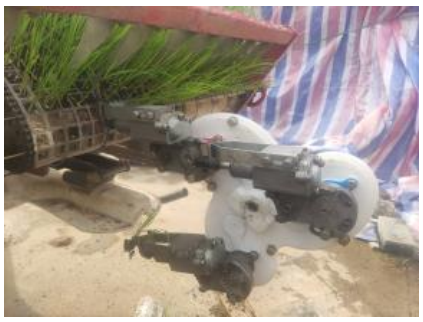

d. Planting
Figure 9 Seedling picking test 


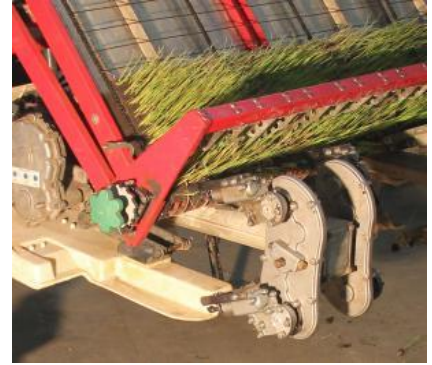

a. Two-arm mechanism

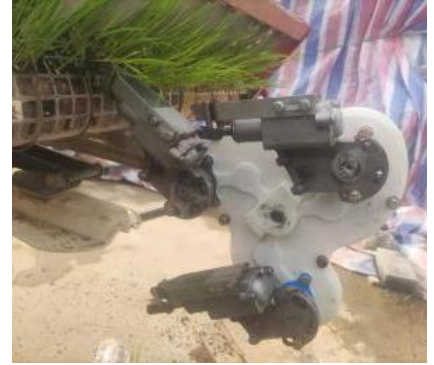

b. Three-arm mechanism
Figure 10 Comparative experiment

\section{Conclusions}

1) This study proposes a three-arm transplanting mechanism for rice potted seedlings. Through the unequal speed transmission of the non-circular gear train, the transplanting mechanism realizes the actions of picking, transporting and planting, which effectively solves the problems of damage to seedlings and missing seedling. It has important practical significance for mechanized transplanting of rice potted seedlings.

2) Based on the self-developed optimal design software of three-arm transplanting mechanism for rice potted seedlings, the influence of each mechanism parameter on the transplanting performance was analyzed. The "parameter guided" heuristic optimization algorithm was used to optimize a set of mechanism parameters so that the transplanting arm can meet the trajectory and attitude required by the rice potted seedlings.

3) A three-arm transplanting mechanism test system for rice potted seedlings was developed, and the transplanting seedling tests were completed. The experiment showed that when the seedling extraction efficiency is 180 holes/min, the seedling injury rate is $0.04 \%$, the seedling missing rate is $1.4 \%$, the seedling pot matrix integrity rate is $96 \%$, and the picking seedling success rate is $99.92 \%$.

\section{Acknowledgements}

This study was financially supported by the National Natural Science Foundation of China (Grant No. 52005221), the Natural Science Foundation of Jiangsu Province (Grant No. BK20200897), and the China Postdoctoral Science Foundation (Grant No. 2021M691315).

\section{[References]}

[1] Zhang H C, Zhu C C, Huo Z Y, Xu K, Jiang X H, Chen H C, et al. Advantages of yield formation and main characteristics of physiological and ecological in rice with nutrition bowl mechanical transplanting. Transactions of the CSAE, 2013; 29(21): 50-59. ( in Chinese)

[2] Zhou J S, Wang L Y, Wu W G, Xu Y Z. Comparison of the cultivation methods between the rice potted seedling and the traditional carpet seedlings. Journal of Anhui Agri. Sci. 2016; 44(7): 22-23, 25. (in
Chinese)

[3] Li Z H, Ma X, Li X H, Chen L T, Li H W, Yuan Z C. Research progress of rice transplanting mechanization. Transactions of the CSAM, 2018; 49(5): 1-20. (in Chinese)

[4] Chen J N, Zhao Y, Yu G H, Zhang G F, Li G. Establishment and verification of dynamics model of seedling-pushing device in transplanting mechanism with planetary elliptic gears. Transactions of the CSAE, 2003 19(5): 71-76.

[5] Felezi M E, Vahabi S, Nariman-Zadeh N. Pareto optimal design of reconfigurable rice seedling transplanting mechanisms using multi-objective genetic algorithm. Neural Computing and Applications, 2015; 27(7): 1907-1916.

[6] Chu T T, Zhu D Q, Xiong W, Zhu L N, Zhang S, Jen T C. Optimizing transplanting mechanism with planetary elliptic gears based on multi-body dynamic analysis and approximate models. Procedia Manufacturing, 2019, 35: 1356-1362.

[7] Ye B L, Wu G H, Yu G H, Li L. Design and test on transplanting arm of rotary transplanting mechanism for rice pot-seedling. Transactions of the CSAM, 2015; 46(7): 45-52. (in Chinese)

[8] Zhao X, Chen J N, Wang Y, Zhao Y, Li C L. Reverse design and analysis of rice seedling transplanter with D-shape static trajectory. Transactions of the CSAE, 2012; 28(8): 92-97. (in Chinese)

[9] Zhao Y, Liu Z P, Xin L, Zhou M L, Wang J. Optimization design and experiment of transplanting mechanism of rice potted seedling on film. Transactions of the CSAM, 2018; 49(4): 87-93. (in Chinese)

[10] Yuan X B, Zhang G F, Chen J N, Zhao Y. Development on rice plotted-seeding sequential transplanter of ejection type. Journal of Zhejiang Sci-Tech University, 2011; 28(5): 749-752. (in Chinese)

[11] Zhang G F, Zhao Y, Chen J N. Development on rice plotted-Seeding sequential transplanter of ejection type. Journal of Zhejiang University (Engineering Science), 2009; 43(3): 529-534. (in Chinese)

[12] Bao C J, Li B F, Bao W Y, Wang R L. Air-sucking sequential rice transplanter for air-pruning tray grown seedlings. Transactions of the CSAE, 2003; 19(6): 130-134. (in Chinese)

[13] Song J N, Wang P, Wei W J, Wang L C. Experimental research on tensile strength of rice seedlings and force of pulling out seedlings from trays. Transactions of the CSAE, 2003; 19(6): 10-13. (in Chinese)

[14] Yu G H, Jin Y, Chang S S, Ye B L, Gu J B, Zhao X. Design and test of clipping-plug type transplanting mechanism of rice plug-seedling. Transactions of the CSAM, 2019; 50(7): 100-108. (in Chinese)

[15] Wu G H, Yu G H, Xiang X J, Wang L W. Design and test of rice potted-seedling transplanting mechanism with three transplanting arms. Transactions of the CSAE, 2017; 33(15): 15-22. (in Chinese)

[16] Wu G H, Yu G H, Ye B L, Yu Y X. Forward-reverse design method for rice potted-seedling transplanting mechanism with compound planetary gear train. Transactions of the CSAM, 2020; 51(2): 85-93. (in Chinese)

[17] Cai J P, Liu M H, Xiao L P, Lin J L, Ye Y Y, Yang H F. Design and experiment of transplanting device with variable row-spacing of rice potted-seedling transplanter. Transactions of the CSAM, 2020; 51(4): 50-59. (in Chinese)

[18] Zhou M L, Sun L, Du X Q, Xin L. Optimal design and experiment of rice potted seedling transplanting mechanism with planetary Bezier gears. Transactions of the ASABE, 2014, 57(6): 1537-1548.

[19] Zhou M L, Hua Z Y, Wang J Y, Wang L, Yin D Q. New type of transverse moving box mechanism for pot seedling transplanting machine. Int J Agric \& Biol Eng, 2018; 11(2): 70-75.

[20] Zhao Y, Zhao X, Dai L, Du X Q, Dai L. Parameter-guided optimization algorithm and its application in designing a rice transplanting mechanism. 2013CCAMMS, 2013. 